\title{
Coenzyme Q10 status, glucose parameters, and antioxidative capacity in college athletes
}

Chien-Chang Ho ${ }^{1,2}$, Ching-Yu Tseng ${ }^{1}$, Hung-Wun Chen ${ }^{3}$, Yi-Wen Chiu' ${ }^{1}$, Ming-Chih Tsai ${ }^{1}$, Po-Sheng Chang ${ }^{3,4}$ and Ping-Ting $\operatorname{Lin}^{3,5^{*}}$ (D)

\begin{abstract}
Background: Glycemia is related to energy production during exercise. Coenzyme Q10 is an antioxidant that participates in adenosine triphosphate synthesis in mitochondria. The aim of this study was to investigate the level of coenzyme Q10, glucose parameters, and antioxidant capacity in athletes.

Methods: This study was designed as a cross-sectional study. Well-trained college athletes $(n=43)$ and age-gender matched healthy subjects $(n=25)$ were recruited from a college. The levels of glucose parameters, oxidative stress, antioxidant enzymes activity, Trolox equivalent antioxidant capacity (TAC), and coenzyme Q10 status were measured in the present study.

Results: The athletes had a significantly lower level of white blood cells (WBC) coenzyme Q10 than the healthy subjects $(0.34 \pm 0.24$ vs. $0.65 \pm 0.43 \mathrm{nmol} / \mathrm{g}, p<0.01)$; however, no significant difference was detected in plasma coenzyme Q10 between the two groups. Regarding the glucose parameters, the athletes had significantly higher values for $\mathrm{HbA1c}(5.5 \pm 0.3$ vs. $5.3 \pm 0.3 \%, p<0.05)$ and quantitative insulin sensitivity check index (QUICKI, $0.37 \pm$ 0.03 vs. $0.34 \pm 0.03, p<0.05$ ), and lower homeostatic model assessment-insulin resistance (HOMA-IR, $1.5 \pm 0.8$ vs. $2.9 \pm 3.8, p<0.05$ ) than the healthy subjects. A higher level of TAC was found in the athletes (serum, $5.7 \pm 0.3 \mathrm{vs}$. $5.4 \pm 0.2 \mathrm{mM}$ Trolox; erythrocyte, $10.5 \pm 0.6$ vs. $10.0 \pm 0.5 \mathrm{mM}$ Trolox, $p<0.05)$. In addition, WBC coenzyme Q10 status was significantly correlated with catalase activity $(r=0.56, p<0.01)$, GPx activity $(r=0.56, p<0.01)$, serum TAC $(r=$ $0.54, p<0.01)$, fasting glucose $(\beta=-1.10, p<0.01), \operatorname{HbA1c}(\beta=-0.82, p<0.01), \operatorname{HOMA}-\mathrm{IR}(\beta=-1.81, p<0.01)$, and QUICK $(\beta=0.08, p<0.01)$.

Conclusions: Athletes may suffer from a marginal coenzyme Q10 deficiency, and the level was related to glycemic control and antioxidant capacity. Further interventional studies are needed to clarify an adequate dose of coenzyme Q10 supplementation in athletes to optimize their coenzyme Q10 status and athletic performance or recovery during exercise.
\end{abstract}

Keywords: Athletes, Coenzyme Q10, Glucose parameters, Antioxidant capacity, Sport nutrition

\footnotetext{
* Correspondence: apt810@csmu.edu.tw

${ }^{3}$ Department of Nutrition, Chung Shan Medical University, Taichung 40201,

Taiwan

${ }^{5}$ Department of Nutrition, Chung Shan Medical University Hospital, Taichung

40201, Taiwan

Full list of author information is available at the end of the article
}

(c) The Author(s). 2020 Open Access This article is distributed under the terms of the Creative Commons Attribution 4.0 International License (http://creativecommons.org/licenses/by/4.0/), which permits unrestricted use, distribution, and reproduction in any medium, provided you give appropriate credit to the original author(s) and the source, provide a link to the Creative Commons license, and indicate if changes were made. The Creative Commons Public Domain Dedication waiver (http://creativecommons.org/publicdomain/zero/1.0/) applies to the data made available in this article, unless otherwise stated. 


\section{Background}

Adequate nutrients and energy intake are required for the health and exercise performance of athletes [1]. Carbohydrates are the major fuel for athletes, and athletes with high insulin sensitivity may increase carbohydrate storage in the form of glycogen for athletic performance [2]. Blood glucose and insulin responses may be involved in the regulation of carbohydrate and lipid oxidation to produce energy for skeletal muscle contractions during exercise [3, 4]; therefore, glycemic control in athletes is an important factor of sports nutrition. In the human body, pancreatic $\beta$-cells are responsible for blood glucose regulation, but they contain lower level of antioxidative enzymes and are sensitive to oxidative damage [5]. Many studies have indicated that athletes have increased production of reactive oxygen species during high-intensity training, which contributes to high oxidative stress, thereby resulting in muscle protein loss, fatigue, injury, and reduced physical performance [6-8].

Coenzyme Q10 is a lipid-soluble nutrient that participates in the mitochondrial respiratory chain for adenosine triphosphate (ATP) synthesis $[9,10]$. Athletes require immediate energy for exercise; however, few studies have investigated the coenzyme Q10 status of athletes. Our previous clinical study of individuals with type 2 diabetes found that the relationship of coenzyme Q10 concentration with glycemic regulation may be medicated through its antioxidant capacity [11]. Thus, the correlation between coenzyme Q10 status and glucose and antioxidant activity in athletes should be explored. The purpose of the present study was to investigate the level of coenzyme $\mathrm{Q} 10$, glucose parameters, and antioxidant capacity in athletes and examine the relationships among these factors. We hypothesized that the level of coenzyme Q10, glucose parameters, and antioxidant capacity in athletes might differ from those in healthy subjects.

\section{Methods}

\section{Participants and study design}

This study was designed as a cross-sectional study. Well-trained athletes and healthy college students were recruited from $\mathrm{Fu}$ Jen Catholic University in Taiwan. The inclusion criteria were as follows: athletes were required to train for more than $12 \mathrm{~h}$ every week, and healthy subjects were required to not train regularly (less than $12 \mathrm{~h}$ every week) and were age- and gendermatched with the athletes. The exclusion criteria were age younger than 18 years, the consumption of nutritional or coenzyme Q10 supplements, and the use of anti-hyperlipidemia or anti-thrombin agents. This study was approved by the Institutional Review Board of $\mathrm{Fu}$ Jen Catholic University, Taiwan (FJU-IRB C105132). Each subject participated in the study after providing written informed consent.

\section{Demographic assessments}

A questionnaire was used to determine the characteristics, including gender, age, and lifestyle habits, of the subjects. The height, weight, and waist circumference of each subject were measured, and then, the body mass index and waist hip ratio were calculated. We used the International Physical Activity Questionnaires (IPAQ) to assess subjects' activity. The unit used was metabolic equivalent of task (MET)-minutes/week. One MET was defined as the amount of oxygen consumed when sitting at rest and was equal to $3.5 \mathrm{ml}$ oxygen $/ \mathrm{kg}$ body weight/ minutes [12].

\section{Hematologic measurements}

Fasting blood samples were collected in vacutainers containing K2-EDTA anticoagulant (Becton Dickinson, Franklin Lakes, NJ, USA) or sodium fluoride (Sparsh Mediplus, Mumbai, Maharashtra, India); serum was separated in the tube without anticoagulant. Plasma, buffy coat layer, erythrocytes, and serum samples were obtained after centrifugation at $4{ }^{\circ} \mathrm{C}$ and $3000 \mathrm{rpm}$ for 15 min. White blood cells (WBC) were obtained from buffy coats layers using red blood cells (RBC) lysis buffer [13].

Hematologic data, such as glucose, insulin, lipid profiles, albumin, blood urea nitrogen, creatinine, creatine phosphokinase, lactate dehydrogenase, alkaline phosphatase, glutamic oxaloacetic transaminase, glutamic pyruvic transaminase, and uric acid levels, were analyzed by an automated chemistry analyzer (Roche, Cobas 8000, Basel, Switzerland), glycated hemoglobin (HbA1c) was analyzed by an automated glycated hemoglobin analyzer (Trinity Biotech, Bray, Co., Wicklow, Ireland), and total lymphocyte count was measured by a hematology analyzer (Sysmex, XN-3000, Kobe, Japan). Then, we further calculated markers of insulin resistance, and the following formulas were used: homeostatic model assessment-insulin resistance $($ HOMA-IR) $=$ glucose $(\mathrm{mmol} / \mathrm{L}) \times$ insulin $(\mu \mathrm{U} / \mathrm{mL}) / 22.5 ;$ homeostatic model assessment- $\beta$-cell function $($ HOMA- $\beta)=20 \times$ insulin $(\mu \mathrm{U} / \mathrm{mL}) /($ glucose $(\mathrm{mmol} / \mathrm{L})-3.5)$ [14]; and quantitative insulin sensitivity check index (QUICKI) $=1 /[\log$ insulin $(\mu \mathrm{U} / \mathrm{mL})+\log$ glucose $(\mathrm{mg} / \mathrm{dL})][15]$.

\section{Oxidative stress and antioxidant enzymes measurements}

Malondialdehyde as an oxidative stress indicator, was determined in plasma and erythrocytes by the thiobarbituric acid reactive substance method [16]. Antioxidative enzymes activity was determined in erythrocytes by calculating changes in the absorbance value of the substance by spectrophotometry. The activities of superoxide dismutase (SOD), catalase (CAT), and glutathione peroxidase (GPx) were measured at $325 \mathrm{~nm}, 240 \mathrm{~nm}$, and $340 \mathrm{~nm}$, respectively [17-19]. A BCA protein assay kit (Thermo, Rockford, IL, USA) was used to determine the protein concentration 
in erythrocytes to adjust antioxidative enzyme activity. A Trolox equivalent antioxidant capacity assay was used to determine the total antioxidant capacity (TAC) in serum and erythrocytes at $730 \mathrm{~nm} \mathrm{[20].}$

\section{Coenzyme Q10 status measurement}

Coenzyme Q10 status was measured by highperformance liquid chromatography (HPLC) with an ultraviolet detector. The plasma coenzyme Q10 analysis was performed according to Littarru et al. [21]. The WBC pellet sample was added to $100 \mu \mathrm{L}$ propanol until it was homogeneous and was then measured using the same process as that used for plasma. The analysis column used was a LiChroCART ${ }^{\oplus} \mathrm{RP}-18$ (Merck, Germany), and the ultraviolet detector was set at $275 \mathrm{~nm}$.

\section{Statistical analysis}

This was an exploratory study. Descriptive statistics are presented as the mean \pm standard deviation (median) or percentages. The Shapiro-Wilk test was used to examine the normality of data distribution. Student's t-test or Mann-Whitney rank sum test was used to examine the differences in coenzyme Q10, glucose parameters, oxidative stress, and antioxidant capacity between the two groups. A chi-square test or Fisher's exact test was used to compare the differences in categorical variables. Spearman's rank order correlation analyses and simple linear regression analyses were used to examine the correlations between coenzyme Q10 status and glucose parameters or antioxidant capacity in athletes. All statistical tests in the study were conducted using SigmaPlot software (version 12.0, Systat, San Jose, California, USA). The statistical significance level was set at a $p$ value $\leq 0.05$.

\section{Results}

\section{Subject characteristics}

The characteristics of the athletes and healthy subjects are shown in Table 1. Forty-three athletes and twentyfive healthy subjects with a mean age of 20 years participated in this study. The ratio of males to females was approximately $2: 1$. The types of sports were taekwondo and soccer, accounting for 49 and 51\%, respectively. There was no significant difference in anthropometric or lifestyle habit data between the two groups. With regard to the activity, the athletes had a significantly higher MET of total physical activity, moderate-intensity activity, and vigorous-intensity activity $(p<0.01)$ and a significantly lower time spent sitting than healthy subjects $(p<0.01)$. For hematological values, the levels of blood urea nitrogen and HDL-C were significantly higher in athletes than in the healthy group $(p<0.05)$; in contrast, the levels of alkaline phosphatase and triglyceride were significantly lower in athletes than those in the healthy group $(p<0.05)$.

\section{Glucose parameters, oxidative stress, and antioxidant capacity}

The levels of glucose parameters, oxidative stress, antioxidative enzymes activity, and total antioxidant capacity are shown in Table 2. The athletes had significantly higher levels of $\mathrm{HbA}_{\mathrm{C}}(p=0.01)$ and QUICKI $(p<0.01)$ than the healthy subjects, while significantly lower levels of insulin and HOMA-IR were found in the athletes $(p<0.01)$. Although there was no significant difference in oxidative stress and antioxidant enzymes activity between the two groups, the athletes had significantly higher levels of TAC in the serum and erythrocytes than the healthy subjects $(p<0.01)$.

\section{Coenzyme Q10 status}

Figure 1 shows the coenzyme Q10 status in the athletes and healthy subjects. The athletes had significantly lower level of WBC coenzyme Q10 than the healthy subjects $(0.34 \pm 0.24 \mathrm{nmol} / \mathrm{g} \quad$ vs. $0.65 \pm 0.43 \mathrm{nmol} / \mathrm{g}, \quad p<0.01)$. However, there was no significant difference in plasma coenzyme Q10 $(0.54 \pm 0.17 \mu \mathrm{M}$ vs. $0.52 \pm 0.11 \mu \mathrm{M}, p=$ $0.56)$.

\section{Correlations between coenzyme Q10 status and antioxidant capacity}

The correlations between coenzyme Q10 status and antioxidant capacity in athletes are shown in Table 3. Coenzyme Q10 status was significantly positively correlated with CAT activity (plasma coenzyme Q10, $r=0.50$, $p<0.01$; WBC coenzyme Q10, $r=0.56, p<0.01$ ), GPx activity (plasma coenzyme Q10, $r=0.49, p<0.01$; WBC coenzyme Q10, $r=0.56, p<0.01)$, and serum TAC (plasma coenzyme Q10, $r=0.37, p<0.05$; WBC coenzyme Q10, $r=0.54, p<0.01)$.

\section{Correlations between coenzyme Q10 status and glucose parameters}

The correlations between coenzyme Q10 status and glucose parameters in athletes are shown in Fig. 2. Coenzyme Q10 status was significantly negatively correlated with glucose parameters, such as fasting glucose (plasma coenzyme Q10, $\beta=-0.74, p=0.04$; WBC coenzyme Q10, $\beta=-1.10, \quad p<0.01$ ), HbA1c (plasma coenzyme $\mathrm{Q} 10, \beta=-0.51, p=0.05$; WBC coenzyme Q10, $\beta=-$ $0.82, p<0.01$ ), and HOMA-IR (plasma coenzyme Q10, $\beta=-1.42, p=0.04 ; \mathrm{WBC}$ coenzyme Q10, $\beta=-1.81, p<$ 0.01 ), and significantly positively correlated with QUICK (plasma coenzyme Q10, $\beta=0.04, p=0.08$; WBC coenzyme Q10, $\beta=0.08, p<0.01)$. 
Table 1 Characteristics of subjects

\begin{tabular}{|c|c|c|}
\hline & Athletes & Healthy subjects \\
\hline Male/Female (n) & $27 / 16$ & $17 / 8$ \\
\hline Age (years) & $19.7 \pm 1.3(20.0)^{1}$ & $19.7 \pm 1.1(20.0)$ \\
\hline \multicolumn{3}{|l|}{ Sports } \\
\hline Taekwondo (n, \%) & $21(49 \%)$ & - \\
\hline Soccer $(n, \%)$ & $22(51 \%)$ & - \\
\hline \multicolumn{3}{|l|}{ Anthropometry } \\
\hline BMI $\left(\mathrm{kg} / \mathrm{m}^{2}\right)$ & $22.1 \pm 2.1(21.5)$ & $22.3 \pm 2.6(22.1)$ \\
\hline Waist hip ratio & $0.79 \pm 0.04(0.79)$ & $0.79 \pm 0.06(0.78)$ \\
\hline \multicolumn{3}{|l|}{ Activity (MET-minutes/week) } \\
\hline Total physical activity & $17,610.5 \pm 7781.7(16,800.0)^{*}$ & $7351.7 \pm 5643.2(6178.0)$ \\
\hline Moderate-intensity activity & $3384.3 \pm 2390.5(2880.0)^{*}$ & $1443.2 \pm 1682.9(800.0)$ \\
\hline Vigorous-intensity activity & $12,485.6 \pm 5759.6(12,480.0)^{*}$ & $4345.6 \pm 3606.0(3600.0)$ \\
\hline Time spent sitting (min/day) & $45.9 \pm 34.8(35.0)^{*}$ & $349.1 \pm 237.8(325.7)$ \\
\hline \multicolumn{3}{|l|}{ Lifestyle habits } \\
\hline Current smokers $(n, \%)$ & $4(9 \%)$ & $6(24 \%)$ \\
\hline Current drinkers $(n, \%)$ & $3(7 \%)$ & $3(12 \%)$ \\
\hline \multicolumn{3}{|l|}{ Hematology } \\
\hline Albumin (g/dL) & $49.9 \pm 2.5(50.0)$ & $50.5 \pm 3.2(51.0)$ \\
\hline Total lymphocyte count (cell/ $/ \mathrm{mm}^{3}$ ) & $2177.0 \pm 638.8(2052.8)$ & $2229.9 \pm 635.5(2163.4)$ \\
\hline BUN (mmol/L) & $5.2 \pm 1.0(5.4)^{*}$ & $4.6 \pm 0.9(4.6)$ \\
\hline Creatinine $(\mu \mathrm{mol} / \mathrm{L})$ & $79.6 \pm 17.7(79.6)$ & $79.6 \pm 17.7(79.6)$ \\
\hline $\mathrm{eGFR}\left(\mathrm{mL} / \mathrm{min} / 1.73 \mathrm{~m}^{2}\right)$ & $103.7 \pm 13.5(103.4)$ & $102.0 \pm 10.5(104.2)$ \\
\hline $\mathrm{ALP}(\mathrm{U} / \mathrm{L})$ & $68.4 \pm 27.3(61.0)^{*}$ & $81.1 \pm 19.6(81.0)$ \\
\hline GOT (U/L) & $19.0 \pm 5.3(18.0)$ & $22.9 \pm 9.5(22.0)$ \\
\hline GPT (U/L) & $15.3 \pm 7.6(13.0)$ & $20.2 \pm 10.1(21.0)$ \\
\hline Uric acid ( $\mu \mathrm{mol} / \mathrm{L})$ & $350.9 \pm 71.4(356.9)$ & $327.1 \pm 77.3(333.1)$ \\
\hline $\mathrm{TC}(\mathrm{mmol} / \mathrm{L})$ & $4.4 \pm 0.8(4.2)$ & $4.4 \pm 0.8(4.4)$ \\
\hline $\mathrm{TG}(\mathrm{mmol} / \mathrm{L})$ & $0.74 \pm 0.51(0.62)^{*}$ & $0.89 \pm 0.44(0.710)$ \\
\hline LDL-C (mmol/L) & $2.5 \pm 0.7(2.3)$ & $2.6 \pm 0.7(2.4)$ \\
\hline $\mathrm{HDL}-\mathrm{C}(\mathrm{mmol} / \mathrm{L})$ & $1.8 \pm 0.4(1.8)^{*}$ & $1.6 \pm 0.3(1.6)$ \\
\hline CPK (U/L) & $315.6 \pm 239.5(213.0)$ & $398.0 \pm 573.2(267.0)$ \\
\hline $\mathrm{LDH}(\mathrm{U} / \mathrm{L})$ & $200.3 \pm 38.9$ (193.0) & $210.2 \pm 45.9(211.0)$ \\
\hline
\end{tabular}

${ }^{1}$ mean \pm SD (median). ${ }^{*} p<0.05$. ALP, alkaline phosphatase; BMI body mass index; BUN blood urea nitrogen; CPK creatine phosphokinase; eGFR estimated glomerular filtration rate; GOT glutamic oxaloacetic transaminase; GPT glutamic pyruvic transaminase; $H D L-C$ high density lipoprotein-cholesterol; $L D H$ lactate dehydrogenase; $L D L-C$ low density lipoprotein-cholesterol; $M E T$ metabolic equivalent; $T C$ total cholesterol; $T G$ triglyceride

\section{Discussion}

Physical exercise may affect glucose dynamics [22] by improving insulin sensitivity [23]. In this study, the athletes showed a higher QUICKI value than the subjects without regular exercise training; however, it is worth noting that athletes had a significantly higher HbA1c level, although the values were within the normal range (Table 2). Lippi et al. [24] also found similar results; elite athletes and cyclists had a significantly lower fasting glucose level but exhibited a trend toward higher HbA1c values than sedentary controls. Recently, Lippi et al. [25] further investigated the fasting glucose and $\mathrm{HbA1c}$ values in endurance athletes and found that HbA1c values seemed to be slightly increased $(p=0.09)$ up to $24 \mathrm{~h}$ after a $21.1 \mathrm{~km}$ marathon run, but the level of fasting glucose was significantly decreased after the run (before run: $4.7 \mathrm{mmol} / \mathrm{L}$ decreased to $4.3 \mathrm{mmol} / \mathrm{L}, p<0.01$ ). It is recommended that athletes consume high glycemic index foods prior to, during and after exercise to elevate the blood glucose levels $[4,26]$. Consuming high glycemic index foods can optimize exercise performance and induce adequate muscle glycogen re-synthesis for 
Table 2 Glucose parameters, oxidative stress, and antioxidant capacity of the subjects

\begin{tabular}{|c|c|c|}
\hline & Athletes & Healthy subjects \\
\hline \multicolumn{3}{|l|}{ Glucose parameters } \\
\hline Fasting glucose (mmol/L) & $4.8 \pm 0.4(4.8)$ & $5.1 \pm 0.6(4.9)$ \\
\hline $\mathrm{HbA1} C(\%)$ & $5.5 \pm 0.3(5.5)^{*}$ & $5.3 \pm 0.3(5.3)$ \\
\hline Insulin (pmol/L) & $47.9 \pm 22.2(41.0)^{*}$ & $88.2 \pm 97.7(66.7)$ \\
\hline HOMA-IR & $1.5 \pm 0.8(1.2)^{*}$ & $2.9 \pm 3.8(2.0)$ \\
\hline HOMA- $\beta(\%)$ & $106.6 \pm 39.2(98.6)$ & $172.1 \pm 136.4(138.6)$ \\
\hline QUICKI & $0.37 \pm 0.03(0.37)^{*}$ & $0.34 \pm 0.03(0.35)$ \\
\hline \multicolumn{3}{|l|}{ Oxidative stress } \\
\hline Plasma MDA ( $\mu \mathrm{M})$ & $2.4 \pm 0.4(2.4)$ & $2.4 \pm 0.4(2.4)$ \\
\hline Erythrocyte MDA (nmol/mg protein) & $3.8 \pm 0.3(3.8)$ & $3.8 \pm 0.3(3.8)$ \\
\hline \multicolumn{3}{|l|}{ Antioxidant capacity } \\
\hline SOD (U/mg protein) & $28.6 \pm 10.9(27.9)$ & $27.9 \pm 9.4(26.9)$ \\
\hline CAT (U/mg protein) & $36.2 \pm 6.1(35.6)$ & $34.4 \pm 7.1(35.2)$ \\
\hline GPx (U/mg protein) & $22.7 \pm 4.1(22.8)$ & $21.1 \pm 2.8(20.9)$ \\
\hline Serum TAC (mM Trolox) & $5.7 \pm 0.3(5.8)^{*}$ & $5.4 \pm 0.2(5.4)$ \\
\hline Erythrocyte TAC (mM Trolox) & $10.5 \pm 0.6(10.5)^{*}$ & $10.0 \pm 0.5(10.0)$ \\
\hline
\end{tabular}

recovery [4]. In the present study, $28 \%$ of the athletes had a high HbA1c level ( $\geq 5.5 \%)$; however, none of the healthy subject had a high HbA1c level. Thus, we suggest that athletes may face the challenge of glycemic control during exercise training and workload, and monitoring their blood glucose levels, such as HbA1c, should be considered. Further studies should detect the susceptibility to diabetes in athletes who consume high glycemic index foods for a long period.

Previous studies have observed that athletes may suffer from coenzyme Q10 deficiency due to sustained heavy physical exertion [27, 28]. Athletes may exhibit a lower coenzyme Q10 status because they have high metabolic requirements; coenzyme Q10 may be depleted during exercise as a result of energy metabolism and limit athletic performance $[27,28]$. Studies have further noted that athletes with a higher plasma coenzyme Q10 level $(>2.5 \mu \mathrm{M})$ showed better physical performance [29]. In our study, although the level of plasma coenzyme Q10 did not significantly differ from that of healthy individuals, we found that the median level of plasma coenzyme Q10 only reached $0.54 \mu \mathrm{M}$ in the athletes. Moreover, the WBC coenzyme Q10 level was significantly lower in the athletes than in the healthy individuals (Fig. 1). WBC
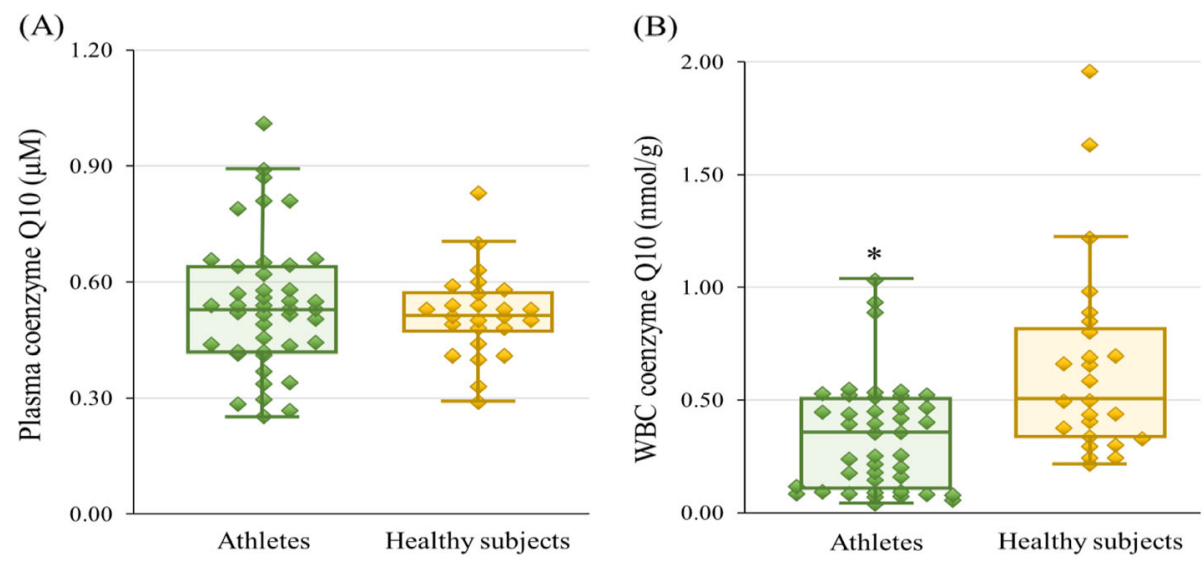

Fig. 1 Coenzyme Q10 status (a) Plasma coenzyme Q10; (b) WBC coenzyme Q10. * $p<0.01$. WBC, white blood cells 
Table 3 Correlations between coenzyme Q10 status and antioxidant capacity in the athletes

\begin{tabular}{lll}
\hline Antioxidant capacity & Coenzyme Q10 status & \\
\cline { 2 - 3 } & Plasma coenzyme Q10 $(\mu \mathrm{M})$ & WBC coenzyme Q10 (nmol/g) \\
\hline SOD (U/mg protein) & $-0.03^{1}$ & -0.12 \\
CAT (U/mg protein) & $\mathbf{0 . 5 0 ^ { * * }}$ & $\mathbf{0 . 5 6 ^ { * * }}$ \\
GPx (U/mg protein) & $\mathbf{0 . 4 9 ^ { * * }}$ & $\mathbf{0 . 5 6 ^ { * * }}$ \\
Serum TAC (mM Trolox) & $\mathbf{0 . 3 7 ^ { * }}$ & $\mathbf{0 . 5 4 ^ { * * }}$ \\
Erythrocyte TAC (mM Trolox) & 0.02 & -0.07 \\
\hline
\end{tabular}

${ }^{1} r$, Spearman rank order correlation coefficients. ${ }^{*} p<0.05 ; * * 0<0.01$

CAT catalase; GPx glutathione peroxidase; SOD superoxide dismutase; TAC total antioxidant capacity; WBC white blood cells
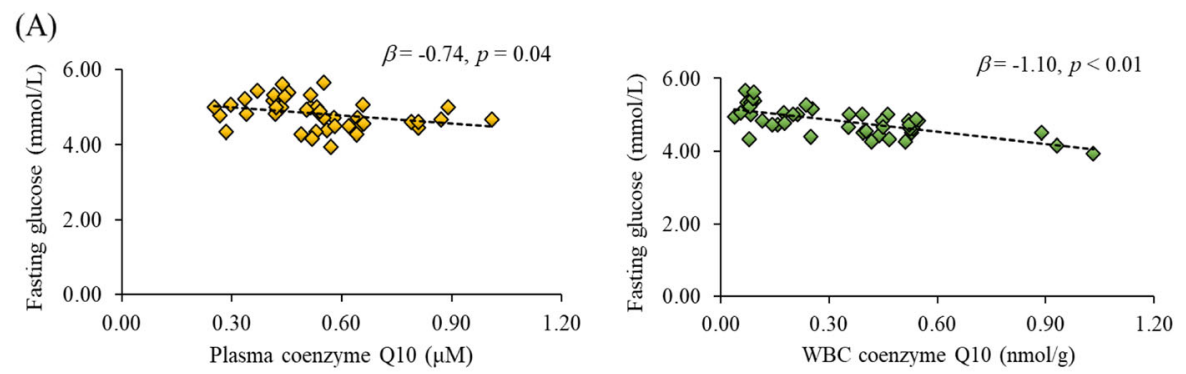

(B)
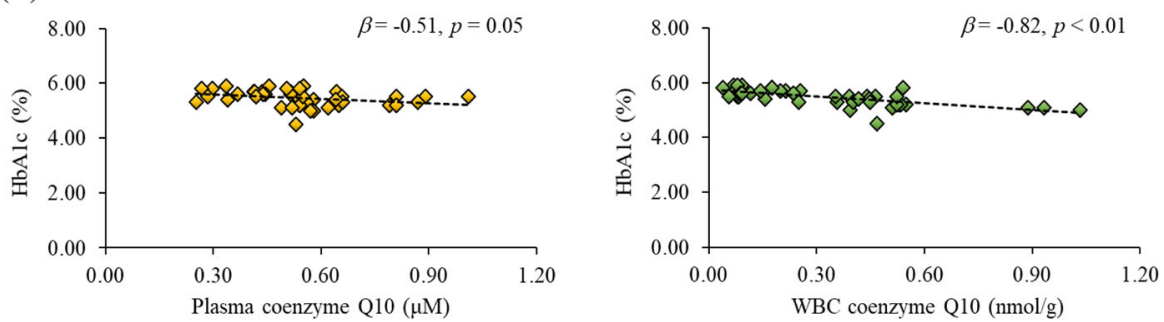

(C)
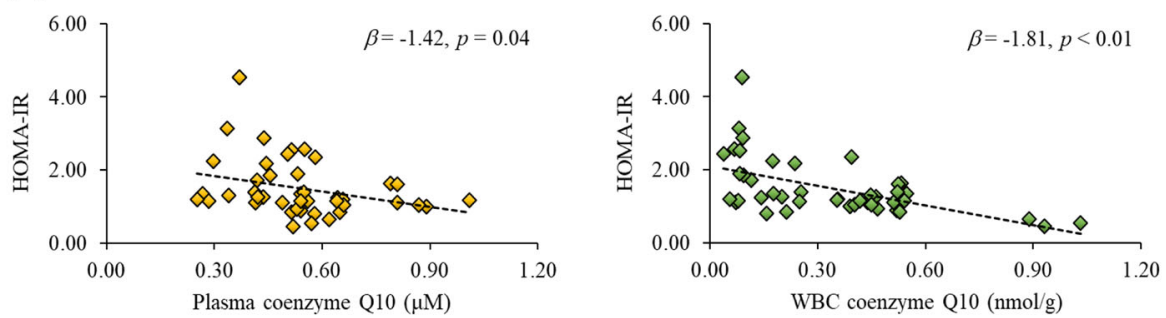

(D)
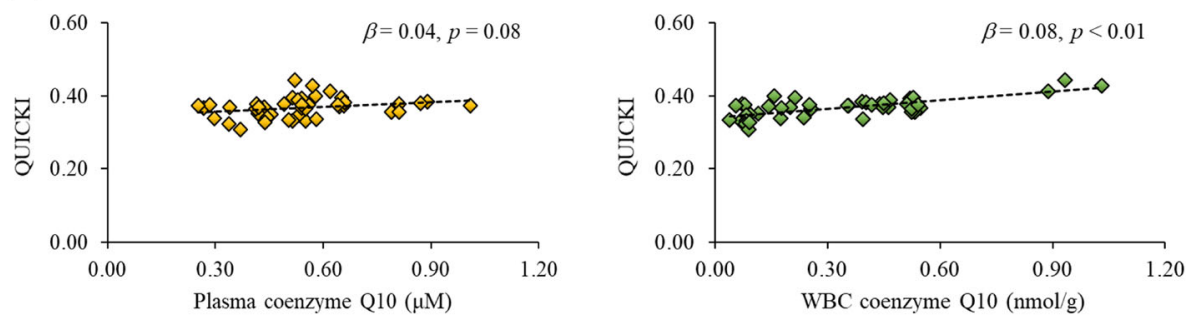

Fig. 2 Correlations between coenzyme Q10 status and glucose parameters in the athletes. a Correlations between coenzyme Q10 status and fasting glucose. $\mathbf{b}$ Correlations between coenzyme Q10 status and HbA1c. c Correlations between coenzyme Q10 status and HOMA-IR. d Correlations between coenzyme Q10 status and QUICKI. HbA1c, glycated hemoglobin; HOMA-IR, homeostatic model assessment-insulin resistance; QUICKI, quantitative insulin sensitivity check index 
with nuclei may possess coenzyme Q10 in mitochondria; therefore, it seems that the coenzyme Q10 status was low in the mitochondria in these athletes. A high coenzyme Q10 status may enhance the peak power production of athletes [27, 29]. In this study, athletes without supplementation showed a low marginal coenzyme Q10 status, and adequate supplementation to improve their coenzyme Q10 status should be assessed.

Coenzyme Q10 is a crucial lipid-soluble antioxidant that can regulate glycemia through its antioxidant capacity to inhibit nuclear factor- $\mathrm{kB}$ (NF-kB) expression, reduce inflammation, and improve insulin sensitivity [5, $11,30]$. In the present study, we found significant correlations between coenzyme Q10 status and glucose parameters (Fig. 2) and antioxidant capacity in athletes (Table 3). We examined the correlations between antioxidant capacity and glucose parameters in athletes (data not shown). The antioxidative enzymes (CAT and GPx) activity and serum TAC were significantly negatively correlated with fasting glucose $(p<0.01)$, HbA1c $(p<$ 0.01 ), and HOMA-IR (CAT, $p=0.01$; serum TAC, $p<$ 0.01 ) and positively correlated with QUICKI (CAT, $p=$ 0.01 ; serum TAC, $r=0.53, p<0.01$ ). As a result, an adequate coenzyme Q10 status could provide better antioxidant capacity and glycemic control in athletes.

\section{Conclusions}

This study is the first to investigate the relationship between coenzyme Q10 status and blood glucose and antioxidative capacity in athletes. Although we could not determine a causal effect in this cross-sectional study, we found that athletes had a marginal coenzyme Q10 deficiency and that the level of WBC coenzyme Q10 may be associated with glycemic control and antioxidant capacity. Further interventional sport nutrition studies are needed to determine the adequate dose of coenzyme Q10 supplementation in athletes to optimize their coenzyme Q10 status to improve athletic performance and recovery during exercise.

\section{Acknowledgments}

We would like to express our sincere appreciation to the subjects for their participation.

\section{Authors' contributions \\ CCH, CYT, HWC, YWC, and MCT performed the study. HWC and PSC performed the data analyses. CCH, HWC, and PSC helped perform the study and sample analyses. CCH, CYT, and PTL conceived the study, participated in its design, and coordinated the study. CCH and PTL drafted the manuscript. All authors read and approved the final manuscript.}

\section{Funding}

This study was supported by a grant from the Ministry of Science and Technology, Taiwan (MOST 106-2410-H-030-065).

\section{Availability of data and materials}

The datasets generated and/or analyzed during the current study are available from the corresponding author on reasonable request.

\section{Ethics approval and consent to participate}

This study was approved by the Institutional Review Board of Fu Jen Catholic University, Taiwan (FJU-IRB C105132), and each subject provided written informed consent before participating. All protocols and procedures were performed according to the Declaration of Helsinki.

\section{Consent for publication}

Not applicable.

\section{Competing interests}

The authors declare that they have no competing interests.

\section{Author details}

${ }^{1}$ Department of Physical Education, Fu Jen Catholic University, New Taipei 24205, Taiwan. ${ }^{2}$ Research and Development Center for Physical Education, Health and Information Technology, College of Education, Fu Jen Catholic University, New Taipei 24205, Taiwan. ${ }^{3}$ Department of Nutrition, Chung Shan Medical University, Taichung 40201, Taiwan. ${ }^{4}$ Graduate Program in Nutrition, Chung Shan Medical University, Taichung 40201, Taiwan. ${ }^{5}$ Department of Nutrition, Chung Shan Medical University Hospital, Taichung 40201, Taiwan.

Received: 8 September 2019 Accepted: 3 January 2020

Published online: 10 January 2020

\section{References}

1. Paquot N. Sports nutrition. Rev Med Liege. 2001;56:200-3.

2. Chen YL, Huang CY, Lee SD, Chou SW, Hsieh PS, Hsieh CC, Huang YG, Kuo CH. Discipline-specific insulin sensitivity in athletes. Nutrition. 2009;25:113742.

3. Mondazzi L, Arcelli E. Glycemic index in sport nutrition. J Am Coll Nutr. 2009;28(Suppl):455S-63S.

4. Walton P, Rhodes EC. Glycaemic index and optimal performance. Sports Med. 1997;23:164-72.

5. Evans JL. Antioxidants: do they have a role in the treatment of insulin resistance? Indian J Med Res. 2007;125:355-72.

6. Kon M, Kimura F, Akimoto T, Tanabe K, Murase Y, Ikemune S, Kono I. Effect of coenzyme Q10 supplementation on exercise-induced muscular injury of rats. Exerc Immunol Rev. 2007;13:76-88.

7. Powers SK, Nelson WB, Hudson MB. Exercise-induced oxidative stress in humans: cause and consequences. Free Radic Biol Med. 2011;51:942-50.

8. Reid MB. Free radicals and muscle fatigue: of ROS, canaries, and the IOC. Free Radic Biol Med. 2008;44:169-79.

9. Littarru GP, Tiano L. Bioenergetic and antioxidant properties of coenzyme Q10: recent developments. Mol Biotechnol. 2007;37:31-7.

10. Turunen M, Olsson J, Dallner G. Metabolism and function of coenzyme Q. Biochim Biophys Acta. 1660;2004:171-99.

11. Yen $\mathrm{CH}$, Chu YJ, Lee BJ, Lin YC, Lin PT. Effect of liquid ubiquinol supplementation on glucose, lipids, and antioxidant capacity in type 2 diabetes patients: a double-blind, randomized, placebo-controlled trial. Brit J Nutr. 2018;25(120):57-63

12. Jetté M, Sidney K, Blümchen G. Metabolic equivalents (METS) in exercise testing, exercise prescription, and evaluation of functional capacity. Clin Cardiol. 1990;13:555-65.

13. Dagur PK, McCoy JP Jr. Collection, storage, and preparation of human blood cells. Curr Protoc Cytom. 2015;73:5.1.1-16.

14. Matthews DR, Hosker JP, Rudenski AS, Naylor BA, Treacher DF, Turner RC. Homeostasis model assessment: insulin resistance and beta-cell function from fasting plasma glucose and insulin concentrations in man. Diabetologia. 1985;28:412-9.

15. Katz A, Nambi SS, Mather K, Baron AD, Follmann DA, Sullivan G, Quon MJ. Quantitative insulin sensitivity check index: a simple, accurate method for assessing insulin sensitivity in humans. J Clin Endocrinol Metab. 2000;85: $2402-10$.

16. Tatum VL, Changchit C, Chow CK. Measurement of malondialdehyde by high performance liquid chromatography with fluorescence detection. Lipids. 1990;25:226-9.

17. Aebi H. Catalase in vitro. Methods Enzymol. 1984;105:121-6.

18. Marklund $\mathrm{S}$, Marklund $\mathrm{G}$. Involvement of the superoxide anion radical in the autoxidation of pyrogallol and a convenient assay for superoxide dismutase. Eur J Biochem. 1974;47:469-74. 
19. Paglia DE, Valentine WN. Studies on the quantitative and qualitative characterization of erythrocyte glutathione peroxidase. J Lab Clin Med. 1967; 70:158-69.

20. Re R, Pellegrini N, Proteggente A, Pannala A, Yang M, Rice-Evans C. Antioxidant activity applying an improved ABTS radical cation decolorization assay. Free Radic Biol Med. 1999;26:1231-7.

21. Littarru GP, Mosca F, Fattorini D, Bompadre S. Method to assay coenzyme Q10 in blood plasma or blood serum. United State Patent. 2007;7303921. https://patentimages.storage.googleapis.com/pdfs/6aadab0bc819eac3443b/ US7303921.pdf.

22. Derouich M, Boutayeb A. The effect of physical exercise on the dynamics of glucose and insulin. J Biomech. 2002;35:911-7.

23. Misra A, Alappan NK, Vikram NK, Goel K, Gupta N, Mittal K, Bhatt S, Luthra K. Effect of supervised progressive resistance-exercise training protocol on insulin sensitivity, glycemia, lipids, and body composition in Asian Indians with type 2 diabetes. Diabetes Care. 2008;31:1282-7.

24. Lippi G, Montagnana M, Salvagno GL, Franchini M, Guidi GC. Glycaemic control in athletes. Int I Sports Med. 2008;29:7-10.

25. Lippi G, Tarperi C, Montagnana M, Danese E, Salvagno GL, Schena F. Challenges of diagnosing diabetes in endurance athletes. J Clin Pathol. 2018;71:945-6.

26. Abernethy PJ, Eden B. Changes in blood glucose levels during a 1005-km running race: a case study. Br J Sports Med. 1992;26:66-8.

27. Alf D, Schmidt ME, Siebrecht SC. Ubiquinol supplementation enhances peak power production in trained athletes: a double-blind, placebo controlled study. J Int Soc Sports Nutr. 2013;10:24.

28. Littarru GP. Energy and defense: facts and perspectives on coenzyme Q10. Biology and medicine. Rome: Casa Editre Scientifica Internazionale. 1995; p. $14-24$.

29. Cooke M, losia M, Buford T, Shelmadine B, Hudson G, Kerksick C, Rasmussen C, Greenwood M, Leutholtz B, Willoughby D, Kreider R. Effects of acute and 14-day coenzyme Q10 supplementation on exercise performance in both trained and untrained individuals. J Int Soc Sports Nutr. 2008;5:8.

30. Evans IL, Maddux BA, Goldfine ID. The molecular basis for oxidative stressinduced insulin resistance. Antioxid Redox Signal. 2005;7:1040-52.

\section{Publisher's Note}

Springer Nature remains neutral with regard to jurisdictional claims in published maps and institutional affiliations.

Ready to submit your research? Choose BMC and benefit from:

- fast, convenient online submission

- thorough peer review by experienced researchers in your field

- rapid publication on acceptance

- support for research data, including large and complex data types

- gold Open Access which fosters wider collaboration and increased citations

- maximum visibility for your research: over $100 \mathrm{M}$ website views per year

At $\mathrm{BMC}$, research is always in progress.

Learn more biomedcentral.com/submissions 